\title{
Lee A. Wilkinson: A Best Practice Guide to Assessment and Intervention for Autism and Asperger Syndrome in Schools
}

\author{
Jessica Kingsley Publishers, London and Philadelphia, 2010, 208 pp, \\ ISBN: 978-1-84905-811-7, \$24.95 (paper)
}

\author{
Oren Shtayermman
}

Published online: 7 July 2010

(C) Springer Science+Business Media, LLC 2010

This book provides a complete source for parents, educators, researchers and clinicians seeking information related to assessment and interventions available for individuals (mostly children) diagnosed with Autism Spectrum Disorders (ASD). Although the book contains significant amounts of scientific terms associated with ASD in research and clinical settings, it is still written in a language that is accessible. There are many examples provided for the terms used as well as how these terms may apply to the process of assessment and intervention. The main reason the book stands out is the application of all the discussed concepts in the two case examples of Jeremy and Sally. Dr. Wilkinson presents a detail and person-centered approach to the stages and issues that needs to be addressed while conducting an assessment and planning interventions for individuals diagnosed with ASD. This is accomplished thorough emphasis on an interdisciplinary approach for assessment and treatment is presented from the start. The book details the crucial collaboration with school professionals for an appropriate assessment and the development of a proper treatment plan. The utilization of screening tools prior to the use of assessment tools is prominently emphasized. Consistent with Evidence Based Practice (EPB), at several points the author makes an attempt to highlight the importance of becoming familiar with at least one screening measure as well as an assessment measure for ASD. The author accentuates the important role of parents in the interdisciplinary approach in the assessment and planning of the interventions. Moreover, since no two individuals diagnosed with ASD are alike, weight is placed on direct child observation in the assessment and treatment planning processes.

The author also places an importance on the incorporation of additional or potential mental health related issues that may have an effect on assessment and intervention. Issues of co-morbidity often can present a challenge to school professionals, clinicians and parents when conducting an assessment with individuals diagnosed with ASD. A true example for EBP guidelines is illustrated when the author introduces the concept of self-management (also known as self-monitoring or Single Subject Design/SSD). Self-management takes into account the individual and builds on personal abilities as part of the assessment and intervention phases. One of the major challenges that may interfere in the process of assessment and planning is the language used in policies to define individuals' diagnosis and whether or not the diagnosis is one that warrants services. Parents will benefit from reading this book as it exposes variety of issues to consider when seeking assessment and treatment for their children. Educators and clinicians can make use of the detailed case examples as those may be applicable to their work environment. In 200 pages, the book is taking the reader step by step in the process that can assist in finding appropriate treatment and settings for individuals diagnosed with ASD. One of the main things I appreciate in the book is the constant reminder of wide spectrum of functioning and strengths individuals on the spectrum present with.
O. Shtayermman $(\bowtie)$

Department of Interdisciplinary Health Sciences, NYIT School of Health Professions, Kenneth Riland - Room 354/366,

Old Westbury, NY 11568-8000, USA

e-mail: oshtayer@nyit.edu 